\title{
Politics and Poetics in Translation of the Classics
}

SHAHEEN SABA

Translators are the shadow heroes of literature, who make it possible for cultures to talk to one another, who have enabled us to understand that we all, from every part of the world, live in one world. -Paul Auster ${ }^{1}$

\section{Abstract}

This paper seeks to uncover the politics surrounding the selection and elimination in the process of translation by presenting instances of the translation of classical masterpieces supported by contemporary postulations. Translation is not a mechanical transposition of words across languages but a cognitive activity that demands active participation of the translator as the individual identity of the translator is not isolated from the process. Most of our acquaintance with the Western and Greek epics has been through English translations and it will not be naive to say that many of these translations have themselves become classics by virtue of various translation strategies. There are multiple manners in which a translation can be approached but none provide a universal model or blueprint for translation as it is not free from the translator's ideology and intervention. Besides cultural appropriation and maintaining equivalences (grammar, style, vocabulary), untranslatability is one of the major challenges for the translators of ancient epic romances such as the Ramayana, the Iliad or the Dastan-e Amir Hamza. Heterogeneous factors compromise the translation of certain sections in classics (the obscene, erotic) that disturb the

\footnotetext{
${ }^{1}$ Auster, Paul. 2007. Foreword to Allen, Esther ed To Be Translated or Not To Be. Diputacio, Institut Ramon Llull. $<$ http://www.pen-international.org/wpcontent/uploads/2011/04/Translation-report_OK-2.pdf>
} 
organicity of a work. Despite the sincere efforts of the translator, the politics of censorship, bowdlerization, publishers and power structures are major impediments of translations and discourses. Therefore, translation becomes an incomplete simulacrum of the original text. Ethically, poetic justice can only be achieved when a text is produced in unexpurgated form as in case of the translation of the Dastane Amir Hamza by Musharraf Ali Farooqi.

Keywords: Translation, classic, untranslatability, epic, dastan.

\section{Let Us Define Translation}

Translation eludes definition by having synonyms such as conversion, paraphrase, version, transformation and change. Each of these synonyms has a different connotation altogether and compromises with translation as we understand it as a transfer of text from one language to another. The synonyms may come into being in process of translation but neither is an appropriate alternative to translation. Translation has been inadequately defined by various practitioners and theoreticians. The word 'translation' is itself very elusive. Casting a glance at history of human civilization one can observe that translation has often been a means of exploring the unknown and assimilating them for enriching one's knowledge vault. If translation or transcendence means to carry over, it is not just a linguistic and verbal carry over, although that is what flashes in one's mind when one thinks about translation. Quite the contrary translation is a loaded baggage since a text is transported from one world to another. Words are highly symbolic with social, economic, historical, aesthetical, political, cultural, mythical and legendary valences. The ambiguity in defining translation goes on to inform the traditional theories on translation. Hence one can only attempt 
and try as best to convey the message and meaning inherent in the source text (Bell 1991).

'The translation should give a complete transcript of the idea of the original work' (Tytler 1790: 9), and also keeps the style and manner as the original. This was a reaction against Dryden's concept of 'paraphrase' which vested the translator with too much liberty. The idea of the original work is the sole output of the author and the translator can only intuit, 'We all translate by intuition'. There is no 'science of translating' (Vermeer 1987). Scientific theories of translation can exist but they are neither applicable nor perfect for translating. Instead of presenting a history of translation or rather summation of the views of theoreticians and practitioners, the paper will critically engage on the nuances of translation of classic epics, the politics of canon formation and censorship with special reference to the translation of epic romances. The paper also lays out the fact that translation is not merely a calculated verbal transfer but a cognitive act which cannot be overlooked because words on a page are a result of cognitive exercise though not deliberate, the translations will always bear the watermark of the translator as the cognitive faculty cannot be separated from the subjectivity of the translator. The translator is also a product of multiple forces (state, family, society, education, law etc.) that garner the cognition, of formulating opinions, priorities and choices, of perceiving things or approaching a text or any reading for that matter.

\section{Translation as a Linguistic and Cognitive Act}

Lawrence Venuti views translation as a process 'that involves looking for similarities between languages and culturesparticularly similar messages and formal techniques-but it does this only because it is constantly confronting dissimilarities' (2008: 264). Translation should not attempt to 
remove these dissimilarities rather it should be a site where different cultures bloom, a space which introduces the reader of the 'cultural other'. 'A translated text should be the site where linguistic and cultural differences are somehow signaled (...)' (ibid.). This strategy based on an 'aesthetic of discontinuity' can best preserve that difference that reflects the distinctness of both the cultures.

Decades ago J. C. Catford defined translation as, "the replacement of textual material in one language (SL) by equivalent textual material in another language (TL)' (1965: 20). This language oriented definition may be the oft quoted definition in Translation Studies but the last three decades have witnessed diverse approaches to translation which interrogate translation beyond replacement of 'textual material' as proposed by Translation Studies scholars like Venuti, Susan Bassnett, Harish Trivedi, Tejaswini Niranjana and others. Bassnett in Reflections on Translation (2011) gives a very clear sketch on some seminal questions on translation and its emergence as a discipline in the last thirty years. No doubt the 'textual material' is derived from the text, but a text can no longer be defined as words on a page, rather it is an amalgam of cultural and metaphorical signifiers and signifieds. The text is interdisciplinary, plural and irreducible post Roland Barthes distinction between a work and a text. Translation Studies has turned more accommodative towards the diverse specters of translation for instance, multilingualism, retranslations, gender and translation, cultural turn, children's literature, scandals, media and translation, post- colonial, legal translations etc. It has travelled from the task of translator to the identity of translator to its invisibility. Post the 'death of author', we may witness the 'birth of the translator' very soon.

Translation is "what happens linguistically and cognitively as the translator works on the translation' (Hatim and Munday 
2004: 346). This is reiterated by Jean Delisle, Hannelore Lee Jahnke and Monique C. Cormier in Translation Terminology (1999) where they seek to bring a homogenization in the existing multiple definitions. Delisle defines translation process as 'the cognitive activity where 'translators' establish inter-lingual 'equivalences' between 'texts' or text segments'. The text is divided into four parts; the same basic text is translated in four languages- French, Spanish, English and German. The compilers of this dictionary conducted a study of eighty-eight teaching handbooks published since World War II. Their studies yielded 838 concepts and 1419 terms from fifteen handbooks related to translation. This compilation of terminology challenges the authors of other such compilation to establish the basic vocabulary that can be useful to university professors, who practise and teach translation. The editors add that their goal throughout this dictionary is to bring clarity and uniformity to those concepts that previously had imprecise definitions and that often have been used in translation courses in university settings. The work that these terminologists have put together is very handy for the 'practical functional terminology' to meet the needs of these users of translation handbooks.

\section{Dastan-e Amir Hamza in Translation}

The Dastan-e Amir Hamza is a seminal existing epic romance in Urdu in India. This four volume epic is the exclusive representative text of the dastan genre. Dastan basically means a long story. It existed in the oral form and was passed down from one generation to another by the masters to their pupils. The narrators were called dastangos (storytellers) who narrated marvelous stories from Dastan-e Amir Hamza to gatherings in the street and court. Musharraf Ali Farooqi has translated it into English in an expurgated form as the The Adventures of Amir Hamza (2007), this translation has been made from 
Ghalib Lakhnavi and Abdullah Bilgrami version which was published by Naval Kishore Press in 1871. Keeping the intentional fallacy aside the intention of the translator for choosing a particular text for translation may be important. In the preface to The Adventures of Amir Hamza, Musharraf Ali Farooqi clarifies that his personal fascination with this book as a young boy led him to translate this text so that the world can know that Urdu literature has such a fascinating epic romance that transposes one to another realm. He was so ensnared by the dastan that the characters visited him in dreams and later he was haunted by them. On a lighter note he set to translate the text so that it is known to the world through English. He also checked if any complete translation of this single volume Ghalib Lakhnavi and Abdullah Bilgrami edition 1871 had been done. Quite obviously Sheikh Sajjad Hussain's slim translation as Dastan-e Amir Hamza: An Oriental Novel (1892) appeared like a short English summary. Frances Pritchett's translation The Romance Tradition in Urdu: Adventures from the Dastan of Amir Hamzah (1991) too appeared unsatisfactory as it had been done from 1969 Maulana Abdul Bari Asi edition, an expurgated version sans the ornamented Urdu. For Farooqi translation of a classical work of such mighty stature can be justified only by reproducing it in its grandeur. Musharraf Ali Farooqi makes some important observations on Pritchett's translation of the 1969 Maulana Abdul Bari Asi edition: "the choice of Asi's version for her translation implies an endorsement of what is inevitably a shortsighted approach, an unredeemable impoverishment' (2000: 170). He wonders at her choice 'to translate a rather callously expurgated version, when scholarship is, and should be, sensitive to the original texts and sources" (ibid.). For him sincere scholarship should not look at marketability or ease of translatability. Thus, he set himself to this mammoth project. Farooqi's translation recalls and reclaims of a lost piece of rich literary heritage, the history 
of our ancestors- the stories/dastan that coloured and lightened North India and bought people together.

\section{Translations of the Classics}

The translation of the Bible has been one of the most talked topics in the world as it is the word of God. Hence one had to be very careful or else face the law (in medieval times they were executed) as seen in case of early translators of the Bible. But the Bible can be used as a metaphor for translation. As for the decades loyalty to the source text was to dominate the translation world. It was the cry of 'word-to-word' and not cultural, semantic or sense for sense as would be developed by later theoreticians. The word becomes sacred and the sanctity must be maintained for translation; the violation of which entails all the possibilities of being labeled as blasphemous.

Besides this, translation is not free from the politics of majority vs. minority language. The attitude of people towards secondary and tertiary languages varies. For instance, in England, Welsh and Scottish appear to be of little importance since the emergence of English as world language (Bassnett 2011). The translation of Bible into native languages and also English had a great impact on respective languages. Bassnett quotes Michael Cronin from Translation and Globalization who remarks that, 'there is an unequal power relationship between minority and majority languages, and hence translation tends to be unidirectional, with the language perceived as least powerful absorbing most from the dominant language which often remains impervious to the other' (2006: 145).

The translations of timeless classics such as Homer's Iliad and Virgil's Aeneid were much safer to deal with. Here they were being assimilated into English which was not a dominant language back in the sixteenth and seventeenth century. 
Alexander Pope and John Dryden, besides others, translated them into English. This was to be followed by many more translations in future, some vibrant hybrids, some original, 'some others are simply cuckoos' as Lorna Hardwick quotes Michael Walton who has briefed up the problematic nature of contemporary 'theatrical response to classic drama'. These works are identified with the cuckoos who smuggle into other's nest and thus hijack the original occupants. The fact that Classics (Greek, Roman Indian etc.) are constantly being translated embody a dual process that of assertion (since translation ascribes value to the source) and subversion (since translation remake texts for new situations and therefore change perceptions of the source). Translations increase the iconic value of the source texts 'as they accumulate meanings and encourage veneration because they situate and resituate the texts at the intersections with the traditions in which they are received they also transform both the texts and their associated iconic status' (Hardwick 2008: 341). The word classic is also not an isolated term that can only be applied to the ancient classical epics such as Homer's Iliad, Virgil's Aeneid, the Ramayana, the Mahabharata or the Dastan-e Amir Hamza. But history has provided us with instances when the translations of these classical epics themselves become classics, for instance, George Chapman's translation of Homer's Iliad and Odyssey in 1616. This can be seen in the light of Lawrence Venuti's observation who suggested that the translations should have a tint of foreignness to familiarize the readers with the fact that they are reading a translation. Susan Bassnett in Reflections on Translations (2011) presents a similar argument where some translators preferred to signal the antiquity of a work in their language of translation. But this Victorian view of medievalizing the language faded because the translators had to deliberately create a language which appeared obscure to the contemporary readers. The translator 
must strive to make a text sound authentic and readable by translating in a language that is comprehensible. This stands quite contrary to Venuti who campaigns against erasing any such traces or presenting a rather smooth translation which makes the translator invisible as the text will be appropriated by the receiving culture as has happened with many classics. But as obvious such translations were welcome by the Romantics $^{2}$ who were enamoured by accessing them for the first time in English translations. John Keats wrote a sonnet 'On First Looking into Chapman's Homer' (1816). The translation gave an epiphanic moment to Keats when he read Chapman's translation of Homer.

The Iliad has been republished by publishers with fresh translations, prefaces, commentary and introduction ever since. Despite being a difficult read, it has been approached in all possible manner but translating a classic demands special competence as 'it is difficult to kill a sheep with dignity in a modern language, to flay and to prepare it for the table, detailing every circumstance of the process' (Cowper 1837: xvii). It has been rendered into blank verse by William Cullen Bryant (1870), adapted literally translated with explanatory notes by Theodore Alois Buckley in 1873. It was further translated by Robert Fitzgerald in 1974 with drawings by Hans Erni. Robert Fagle's version of the Illiad provides us with yet another way to approach Homer. Fagle's Iliad can be taken as an instance to show the various styles employed by the translators while translating classic masterpieces. In the 1990

${ }^{2}$ Lawrence Venuti closely follows the thinking of the German thinker Friedrich Schleimacher whose formulated ideas in the nineteenth century ran contrary to the French school of thinking which upheld deomestication. Venuti's theory of foreignization fine tunes with the post-colonial scholars of translation who do not uphold domestication as it erases the traces of the source text's native identity. 
version Fagle confirms to Matthew Arnold's proposition that translation is a means of empowering the academic elite. Fagle's version was literal in an academic i.e. Arnoldian sense, striking a balance between the 'literal' and the 'literary' which brings it close to John Dryden's concept of 'paraphrase' resulting in a modernized version of Homer (Venuti 2008: 119). But fresh translations have not ceased for instance, the recent translation of the Iliad by Caroline Alexander published by New York, Ecco, an imprint of Harper Collins Publishers in 2015. These are only a handful among the long list but one can deduce from above is that the Iliad has constantly been reassessed for the readers. The reason for the translations themselves becoming classics are varied ranging from the popularity of a translator or scholar or easy availability, or abridgement or clarity. Hence a source text (here the classic) is a classic as it has been canonized, but the journey of a translation attaining the status of a classic has many stories behind it.

Talking about the two translations of the comparatively lesser translated Catullus, states that the marginality of Catullus was due to a combined factor. The epic genre was privileged over lyric in English poetry translation, "But there was also the issue of morality, with English writers at once attracted and disturbed by the Pagan sexuality and the physically coarse language, entertaining a guilty fixation on the poet's scandalous affair with 'Lesbia' (Venuti 2008: 69). Like Dastan-e Amir Hamza which was itself a translation from a Persian version as obvious from Ghalib Lakhnavi's title in Urdu Tarjuma-e Dastan-e Sahibqiran Giti-Sitan Ala-e Paighambar-e Aakhiruz Zaman Amir Hamza bin AbdulMuttalib bin Hashim bin Abdul Munaf, published by Matba-e Hakim Sahib, Calcutta in 1855, the two translations of Catullus (The anonymous Adventures of Catullus and History 
of His Amours and Lesbia (1707) were also translations from French Jean de la Chapelle's Les Amours de Catulle (1725).

A classic translation of a classical epic text is inherently an archival performance of the target culture, one that reinscribes the literary history and norms of the target culture onto the originating space of epic (Armstrong 2008: 169). Philip Lutgendorf, professor of Hindi and Modern Indian Studies at the University launched the project of retranslating Sanskrit epic poem the Ramayana by Tulsidas, a sixteenth version which is written in more standardized Hindi. Lutgendorf remarked that the interest in retranslating this classical epic was to produce a free-verse translation as prior translations 'indulged in a turgid prose' which 'he finds antithetical to the momentum and compression of the original' (Guzman 2015).

Therefore there are multiple reasons behind a fresh translation of a classic. As Musharraf Ali Farooqi opined that prior to his translation there was only one complete translation of Dastane Amir Hamza that was carried out by Frances Pritchett from a 1960 expurgated version edited by Abdul Baari Aasii which according to her was an easier read. But Musharraf Ali Farooqi went straight to the first 1871 edition and dared to translate the classical epic romance passionately and responsibly with all its ornamentation and bulk that reveals the splendor of Dastan-e Amir Hamza. One is struck not with epithets of the same word as Lutgendorf remarks that in Book I of the Ramayana there are twenty nine epithets for 'lotus', but of different words and different ways of presenting the same thing repeatedly and the never ending verities of flora, fauna, dresses, weaponry, horses and troops. Therefore, translation of a classic requires precision in achieving the symmetry and parallelism in the target language. 


\section{Tackling Untranslatability in the Classics}

Untranslatability is one of the major hurdles that a translator has to face at some point or the other. There have been various debates on domestication vs. foreignization, views on retention of source language words and terminologies as some consider that it makes the translation obscure or irritable read while in some cases it becomes an unavoidable necessity. Turning back to classic epics with a work as diverse as Dastan-e Amir Hamza (1871), it becomes unavoidable. Dastan-e Amir Hamza is not located in a fixed geographical location or time thereby we find an abundance of verities; allusion of heroes from Rustam to Alexander, the text travels from Persia to India to Sri Lanka to China. The composition of the text makes it unique in its kind as it has layers of sedimentation over time as it did not enjoy the popularity of running in prints until Munshi Naval Kishore (1836-95) began publishing them from Naval Kishore Press established in 1858. Rare handwritten manuscripts of Dastan-e Amir Hamza dating back to Akbar and even earlier are no longer traceable. The text kept on growing as it landed in various places. For instance, the current text has lot of Indian elements as the dastangos (storytellers) of Lucknow added local flavour to the existing corpus so that the listeners would not feel it to be an estranged narration, this is exemplified through the presence of words such as mangtika, camurbandh, bhagat, katar, bichawa, jamdani, dotara etc. Musharraf Ali Farooqi has translated them at his best. For the untranslatable, he has added detailed notes and list at the end of the English translation.

The politics of publishing houses cannot be dissociated from translations as they cater to texts more accessible to a national reading public as they target profits. Translations of books such as Jellyfish (2008), an experimental novel recounted by a neurotic homosexual man does not feature in the reading list 
because the readerships for such works are 'woefully small'. Translation ideology and poetics cannot be isolated from translatability which involves professionals such as publishers, translators, editors and educators (Lefevere 1992). Along with the patrons of literature, these professionals go on to determine the fate of classics. But ideology and poetics are not fixed entities and hence liable to change with the passage of time. What is mundane today (Jellyfish) may be queued up besides Hamlet and Odyssey tomorrow. Dastan-e Amir Hamza shared the same fate which was not rejected in totality but neither was it considered as 'pure literature', a term which itself is very ambiguous. It enjoyed peripheral status and women of respectable families were advised not to read this particular book as advocated by Maulana Ashraf Ali Thanvi in Bahishti Zewar ${ }^{3}$. Thus canon formation in literature has been flawed in itself; there are no fixed parameters for making a work classic. Art and literature had already been polarized (classic/nonclassic, high/low art, pure/impure, sacred/profane, conformists/ non-conformists etc.); therefore it is either of the pairs.

Attempts are being made to overcome the classic/non-classic barrier through multiplicity of canons as advocated by Emily Apter. World literature is more accommodative towards differences but it is not possible to translate everything or to substitute it for a universally global idiom. This is evident from the fix of untranslatability that every translator faces. The manner in which translation has been included in the umbrella of world literature is perplexing. Although on the one hand,

\footnotetext{
${ }^{3}$ This is an Islamic book on moral conduct and jurisprudence for Muslim women written in Urdu. After its publication it became a household name. It was gifted to the newly wed bride so that she may be able to conduct herself properly at the in-law's house. It has been translated into English by Maulana Mohammad Mahomedi. Barbara Daly Metcalf's book Perfecting Women (1992) is a commentary and history of Bahishti Zewar. $<$ https://archive.org/details/BahishtiZewar_201307 >
} 
this promotes the lesser known texts, on the other hand world literature appears to be ignorant of the linguistic and cultural specificity by anthologizing it as World Literature (Apter 2013). To overcome untranslatability translators intervene to make text simpler for the target audience as postulated by Lefevere, for instance, the modification made by Anneliese Schutz to temper anti-German sentiments in Anne Frank's diary in her translation for Fischer Publishing House in 1955. There are texts that deviate so much from 'acceptable' and 'expected' that the translators simply steer clear of these untranslatable elements (Lefevere 1992).

\section{Translating the Erotic in the Classics}

Vocabularies of sex or obscene or erotic passages pose another major challenge to the translators as they are notoriously difficult to translate. However, it is important to note that there is a very thin line dividing the obscene and erotic as they are determined by the aesthetic reception which vary culturally. The same happens in case of translation of epics as what may appear aesthetically appealing in the source language may appear indecent or obscene in the target language. 'Translators in the late nineteenth and early twentieth century suggest that they are sparing their readers material or language that would be shocking (or repulsive or distasteful) to the translator's contemporaries' (Roberts 2008: 285). There is another high concern that the audience may also be morally corrupted by such texts besides being shocked. This is reflected in the legal rulings against such representations in literature which includes translation of classical texts in the late nineteenth and early twentieth century by organizations such as the New York Society for the Suppression of Vice. In the modern period, D. H. Lawrence's novel such as The Rainbow (1915) had to face censorship and resentment. Lady Chatterley's Lover (1928) 
was banned in the United States till $1959^{4}$ along similar lines. The book was explosive as it showed the physical and emotional relationship between a working class man and an upper class woman. It was a major threat to the vanguards (state and religion) of the society.

The Dastan-e Amir Hamza also suffered a similar fate, the erotic content being one of the contributing factors for not making it to mainstream literature. It is not assumed that a work of merit must be the mainstream, but it is the recognition, the passport that it grants for circulation worldwide that matters. As I have observed, there is also a gender bias involved in the censoring of such texts. As the Dastan-e Amir Hamza initially existed in the oral form, it was meant to be narrated (dastangoi) in public gatherings which hardly comprised of any women. It was safe as long as it did not reach the drawing rooms in print especially for women. Hence after it came out in print by the efforts of Munshi Naval Kishore it was publicly declared unfit for women because it contained erotic lines, lust, rape, sex and obscene pranks played by Amar Ayyar (the trickster) on his adversaries. But the fact that the protagonist (Amir Hamza) is free to wed as many women as he likes, despite promises and commitment dilute the argument. The Dastan-e Amir Hamza has licentious spaces but a warrior (Amir Hamza) is still celebrated for his valour and martyrdom for the cause of Islam. Musharraf Ali Farooqi has, however, not expurgated the text of these scenes by reproducing them craftily in his translation titled The

\footnotetext{
${ }^{4}$ When the full unexpurgated edition was published by Penguin Books in Britain in 1960, the trial of Penguin under the Obscene Publications Act 1959 was a major public event and a test of the new obscenity law. The 1959 act (introduced by Roy Jenkins) had made it possible for publishers to escape conviction if they could show that a work was of literary merit. <https://en.wikipedia.org/wiki/Lady_Chatterley\%27s_Lover>
} 
Adventures of Amir Hamza (2007). The translator has also been successful in translating the vasokht ${ }^{5}$ and sarapa $^{6}$ beautifully.

Some translators, however, prefer to expurgate the text of such elements for various reasons, moral concerns and purification of the text being the primary ones. Some translators of the expurgated editions of classics 'often seek also to justify their decision to conceal or modify those aspects of the text they consider unworthy of the author inappropriate to their intended audience or otherwise un-punishable' (Roberts 2008: 284). Tom Lewis' comments on the problem the Victorian courts faced in distinguishing between works of high art and classic literature and obscenity from his article 'Legislating Morality: Victorian and Modern Legal Responses to Pornography'. He argues that the seekers of such legislation were not concerned about 'the existence or consumption of obscene materials per se' but their availability 'to a much wider reading and viewing public'. Therefore, the translation stands chances of plaguing the sanctity of the home by retaining such passages and the translators should function as moral guards (Roberts 2008: 286).

Apart from this, obscenity was linked to class. This is a stark polarization of society that tends to show the upper class as refined and the lower class as uncouth and uncivilized, and hence such text containing lewd passages cannot adorn their houses. This is a generalization as sex or intimacy which is present in the society irrespective of caste, class or race.

\footnotetext{
5 A form of Urdu poetry, conventionally defined as one in which the lover asserts his pride and self-regard. However, the verses in question do not strictly adhere to this definition.

${ }^{6}$ A grouping of verses in which a poet elaborately details the corporeal beauty of his female beloved
} 
The ancients, in the expression of resentment or contempt, made use of many epithets and appellations which sound extremely shocking to our more polished ears, because we never hear them employed but by the meanest and most degraded of the populace. By similar reasoning we must conclude that those expressions conveyed no such mean or shocking ideas to the ancients since we find them used by the most dignified and exalted characters (Tytler 1790: 145-146).

The labeling of obscenity in literature was heralded in India by the British. The first instance was found in series of reports on the Bengal book trade compiled by James Long for the government in 1850s. Measures to curb obscene literature in India ran parallel to the 1857 Obscene Publications act in Britain. In India 'The earliest Indian obscenity law was the Obscene Books and Pictures Act (Act I of 1856), which imposed a fine or imprisonment for the sale of obscene books or pictures'(Stark 2009: 91). But there was no clear-cut distinction between 'erotic' and 'obscene' and the publishers were left confused.

Forms like vasokht were particularly targeted as they were considered highly erotic. A number of vasokhts also figure in the Dastan-e Amir Hamza. As suggested by Stark the Victorian sensibilities and puritanical hold of Britain was responsible for censor of obscene literature in India. Besides this, the local clerics themselves were critical of the literature being circulated at that time as seen in the case of Maulana Thanvi. As Naval Kishore Press was a major publishing house in the North in late nineteenth century and responsible for publishing many other seminal works besides the Dastan-e Amir Hamza, an editorial was devoted to the question in Avadh Akhbar (the first Urdu daily in North India launched in 1858 from the Naval Kishore Press in Lucknow). Stark says "it was 
typical in offering an apologetic statement to the effect that just as exaggeration was regarded a merit rather than a defect in oriental literature, in the same way 'obscenity couched in a fine language' was considered 'quite an art among the eastern writers"'(2009: 95). There were varied responses from various regions of India as the sanitation of literature came into effect. This can be a reason for triggering what came to be known as 'underground literature' that was sold cheap in bulks. They sold like hot cakes and ran into publications until they were discovered.

In light of the above contestation, it will be apt to say that moral policing of art, literature and translation does not promote a healthy environment for growth of civilization. Undoubtedly, cultural and linguistic divide fringe translations with problematic instances, which a translator tries to overcome with the best possible strategy. But sometimes specific targeted sections (obscene/erotic) of a classic is declared untranslatable not by the translators but by the often pretentious moral vanguards. Translators are doubly vulnerable to be charged for translating something obscene or unpleasant because the vanguards fashion the 'what is readable' and 'what is fit' according to their lenses. Ethically, translation of any text should be fearless, free from the fetters of power and politics. Only then can we introduce a piece of literature gracefully to another culture. As observed Musharraf Ali Farooqi has translated all such passages sans sanitation. This has familiarized the readers of today with the dastan, the epic romance that is known and notoriously famous for trickster's acts, passionate love and war in its original intrinsic form.

\section{References}

Armstrong, R. H. 2008. Classical Translations of the Classics: The Dynamics of Literary Tradition in 
Translating Ancient Epic. In Alexandra Lianeri and Vanda

Zajko (eds.), Translation and the Classic, 169-202. Oxford: Oxford University Press.

APTER, EMILY S. 2013. Against World Literature: On the Politics of Untranslatability. London: Verso.

BASSNetT, SUSAN. 2011. Reflections on Translation. Bristol: Multilingual Matters.

BELL, R. T. 1991. Translation and Translating: Theory and Practice. London: Longman.

CATFORD, J. C. 1965. A Linguistic Theory of Translation: An

Essay in Applied Linguistics. Oxford: Oxford University Press.

COWPER, W. 1802. The Iliad of Homer Translated into English Blank Verse, in The Works of William Cowper, Esq. London: Baldwin \& Cradock. xi.

Delisle, J. (ed.). 1999. Terminologie de la traduction. Amsterdam: John Benjamins.

FAROOQI, Musharraf Ali. 2000. Dastan-e Amir Hamza

Sahibqiran: Preface to the Translation. Annual of Urdu

Studies 15.

HARDWICK, LORNA. 2008. Translated Classics around the Millenium: Vibrant Hybrids or Shattered Icons? In Alexandra Lianeri and Vanda Zajko (eds.), Translation and the Classic. Oxford: Oxford University Press.

HAтім, B. 1997. Communication across Countries:

Translation Theory and Contrastive Text Linguistics.

Exeter: University of Exeter Press.

HATIM, B, and I. MASON. 1997. The Translator as Communicator. London: Routledge.

JAKOBSON, ROMAN. 1959. On Linguistic Aspects of Translation. In R. A. Bower (ed.), On Translation. Cambridge \& MA: Harvard University Press. 
Shaheen Saba

LAKHNAVI, GHalib and ABdullah Bilgrami. 2007. The Adventures of Amir Hamza (Musharraf Ali Farooqi, (trans.) New York: Random House Publishing Group.

LEFEVERE, ANDRE. 1992. Translation Rewriting and Manipulation of Literary Fame. Routledge: New York.

LIANERI, ALEXANDRA and VANDA ZAJKO, (eds.). 2008. Translation and the Classic: Identity as Change in the History of Culture. Oxford: Oxford University Press.

PRICHETT, FRANCIS. 1991. The Romance Tradition in Urdu: Adventures from the Dastan of Amir Hamzah. New York: Columbia University Press.

RoberTs, DeBORAH H. 2008. Translation and Surreptitious Classic: Obscenity and Translatability. In Alexandra Lianeri and Vanda Zajko (eds.), Translation and the Classic. 279-311. Oxford: Oxford University Press.

STARK, UlRIKE. 2009. An Empire of Books. New Delhi: Orient Blackswan.

Steiner, GeORge. 1994. After Babel. New York \& London: Oxford University Press.

VenUti, LAWRENCE. 2008. The Translator's Invisibility.

London \& New York: Routledge.

Vermeer, Hans J. 1987. What does it Mean to Translate. In Gideon Toury (ed.), Translation Across Cultures. 25-33. New Delhi: Bahri Publications Pvt. Ltd. 